\title{
Cervical cannulation for resternotomy in pediatric patients
}

\author{
Ralph E. Delius, MD, ${ }^{a, b}$ Celia Buckley, RN, MSN, ${ }^{c}$ and Henry L. Walters III, MD, a,b Detroit, Mich, and Sacramento, Calif
}

$\mathbf{R}$ esternotomy is a common, albeit challenging, component of many current cardiac operations and remains a source of morbidity and mortality. ${ }^{1-3}$ Despite the recent emphasis on primary repair for congenital heart defects, complete repair or palliation often requires multiple operations. In the vast majority of cases, sternal reentry can be performed without difficulty. However, a small number of patients have anatomic configurations that make sternal reentry particularly hazardous. Potentially difficult sternotomies on occasion require alternate cannulation sites. Typically the femoral vessels are used in larger patients, but these vessels are often unavailable in pediatric patients because of multiple previous cardiac catheterizations, cutdowns, and, in pretoddler infants, inadequate size. The aim of this report is to describe our experience with cervical cannulation in infants undergoing resternotomy.

\section{Methods}

Patients. Six patients have undergone cervical cannulation at two different institutions (2 at University of California Davis Medical Center, Sacramento, Calif, and 4 at Children's Hospital of Michigan, Detroit, Mich). One child had only the common carotid artery cannulated, with venous drainage from the right atrium. The remaining patients had both the right common carotid artery and right internal jugular vein cannulated. The diagnoses and indications for an alternative cannulation site are shown in Table 1.

Technique. Patients were placed on the operating room table in a supine position, with the head facing to the left. A bump was placed under the shoulders to increase cervical extension, and surgical drapes were placed slightly cephalad.

A transverse cervical incision was made over the right sternocleidomastoid muscle, parallel to and approximately 1 to $2 \mathrm{~cm}$ above the clavicle (Figure 1,A). The dissection was performed between the sternal and clavicular heads of the sternocleidomastoid muscle. A Weitlander retractor was sufficient for exposure (Figure 1, B). The internal jugular vein and the common carotid

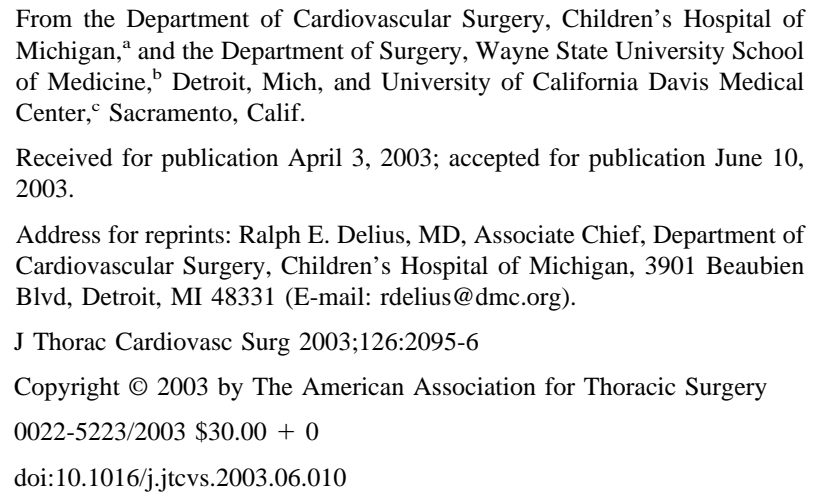

artery were dissected out. After heparinization, polypropylene (5-0 or 6-0) purse-string sutures were then placed on both the internal jugular vein and common carotid artery (Figure 1,C). Our preference is to cannulate the common carotid artery first, followed by internal jugular venous cannulation, but some groups prefer to perform the venous cannulation first. The venous cannula was positioned so that the tip lay within the right atrium. Once bypass was established and the chest was opened, a second venous cannula was usually placed into the interior vena cava or within the right atrium to augment venous return. Decannulation was performed by tying the purse-string sutures.

\section{Results}

All 6 patients survived the operation. Three patients underwent cervical cannulation prophylactically before resternotomy because of particularly hazardous anatomy. The remaining 3 patients were placed on bypass after bleeding was encountered during sternal opening. In each case, the bleeding was controlled by digital pressure by the assistant while the surgeon cannulated the cervical vessels. Three patients have had a follow-up Doppler study of their cervical vessels from 6 months to 2 years after surgery. In each case, all vessels were patent. No complications have been attributed to cervical cannulation.

\section{Discussion}

Sternal reentry remains a challenging problem confronting the surgeon who corrects congenital heart conditions. The vast majority of resternotomies are performed without incident. Nevertheless, a small subgroup of patients have problems with sternal reentry, such as those with a substernal homograft or shunt, a markedly dilated right atrium, or aneurysms of the right ventricular outflow tract. ${ }^{1-3}$ In larger patients femoral cannulation provides ready access for cardiopulmonary bypass, but in younger patients the femoral vessels are too small to cannulate. The iliac vessels are suitably sized but require a retroperitoneal approach. Cervical cannulation was championed by pioneers of extracorporeal membrane oxygenation because of the ready accessibility and satisfactory size for cannulation of this vessel. Concerns about cerebral injury as a result of common carotid ligation in patients undergoing extracorporeal membrane oxygenation are probably not applicable in this case, because the common carotid artery is not ligated, as is frequently done in extracorporeal membrane oxygenation, but rather is cannulated through a purse-string suture, which should allow antegrade flow around the cannula. If the potential need for cervical cannulation is identified before the operation, patency of the right and left internal jugular veins should be confirmed by Doppler study before surgery. Cannulation of the right internal jugular vein in the presence of an occlusion of the left internal jugular vein could lead to cerebral venous hypertension and im- 

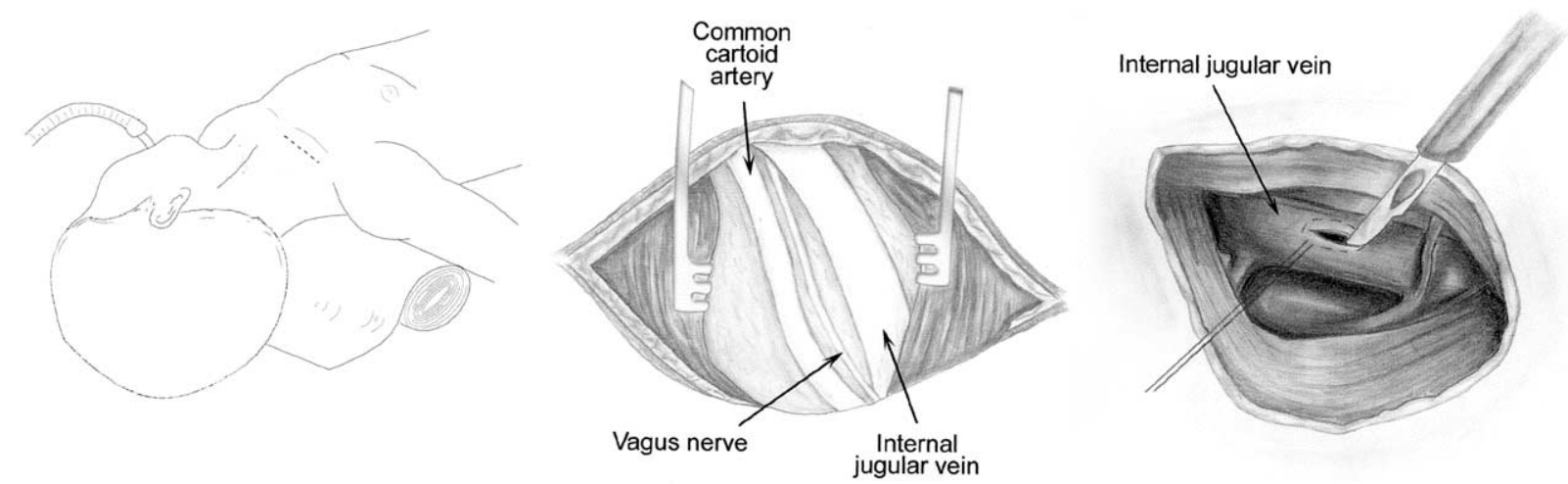

Figure 1. A, Position of patient and site of incision for cervical cannulation. B, Completed dissection before cannulation. C, Cannulation of internal jugular vein. Vascular clamp is omitted for better visualization.

TABLE 1. Clinical summaries

\begin{tabular}{|c|c|c|c|}
\hline Case & Diagnosis & Operation & Indication \\
\hline 1 & $\begin{array}{l}\text { Truncus arteriosus; right ventricle to } \\
\text { pulmonary artery conduit } \\
\text { pseudoaneurysm }\end{array}$ & $\begin{array}{l}\text { Repair pseudoaneurysm; replace right } \\
\text { ventricle to pulmonary artery conduit }\end{array}$ & Prophylactic \\
\hline 2 & $\begin{array}{l}\text { Hypoplastic left heart syndrome, status } \\
\text { post Norwood procedure }\end{array}$ & Hemi-Fontan & $\begin{array}{l}\text { Bleeding - aorta adherent to } \\
\text { sternum }\end{array}$ \\
\hline 3 & $\begin{array}{l}\text { Pulmonary atresia with intact ventricular } \\
\text { septum; discontinuous pulmonary } \\
\text { arteries }\end{array}$ & Pulmonary artery angioplasty & $\begin{array}{l}\text { Bleeding-previously placed } \\
\text { anterior shunt }\end{array}$ \\
\hline 4 & $\begin{array}{l}\text { Pulmonary atresia with ventricular septal } \\
\text { defect; right ventricle to pulmonary } \\
\text { artery conduit pseudoaneurysm }\end{array}$ & $\begin{array}{l}\text { Repair pseudoaneurysm; replace right } \\
\text { ventricle to pulmonary artery homograft }\end{array}$ & Prophylactic \\
\hline 5 & $\begin{array}{l}\text { Truncus arteriosus; right ventricle to } \\
\text { pulmonary artery conduit obstruction }\end{array}$ & $\begin{array}{l}\text { Replace right ventricle to pulmonary artery } \\
\text { homograft }\end{array}$ & $\begin{array}{l}\text { Bleeding-homograft } \\
\text { adherent to sternum }\end{array}$ \\
\hline 6 & $\begin{array}{l}\text { Transposition of the great arteries, status } \\
\text { post arterial switch; pulmonary artery } \\
\text { aneurysm }\end{array}$ & $\begin{array}{l}\text { Repair pulmonary artery aneurysm; bilateral } \\
\text { pulmonary angioplasty }\end{array}$ & Prophylactic \\
\hline
\end{tabular}

paired cerebral perfusion. Complete cannulation of the cervical vessels can be performed in approximately 10 to 15 minutes. Potential complications, such as late vessel occlusion, were not seen in this small series of patients.

Alternative cannulation sites should rarely be needed during resternotomy. However, cervical cannulation provides several advantages relative to femoral cannulation in smaller patients. Risk associated with this cannulation technique appears to be low.

\section{References}

1. DeLeon SY, Ilbawi MN, Tubeszewski K, Wilson WR, Quinones JA, Roberson DA, et al. Resternotomy in patients with valved conduits adherent to the sternum. Ann Thorac Surg. 1991;52:569-71.

2. DeLeon SY, LoCicero J, Ilbawi MN, Idriss FS. Repeat median sternotomy in pediatrics: experience in 164 consecutive cases. Ann Thorac Surg. 1986;41:184-8.

3. Follis FM, Pett SB, Miller KB, Wong RS, Temes RT, Wernly JA, et al. Catastrophic hemorrhage on sternal reentry: still a dreaded complication? Ann Thorac Surg. 1999;68:2215-9. 